\title{
5. LA FINANCIACIÓN DE LOS PARTIDOS POLÍTICOS ANTE LA OPINIÓN PÚBLICA *
}

\author{
PILAR DEL CASTILLO \\ Profesora Titular de Ciencia Política \\ UNED
}

* Este trabajo fue preparado para su presentación en la Conferencia organizada por The Committee on Political Finance de la Asociación Internacional de Ciencia Política, celebrada en Kazimierz Dolny, Polonia del 29 de mayo al 2 de junio de 1989. 


\section{SUMARIO}

INTRODUCCION.-I. LOS PARTIDOS ANTE EL ELECTORADO: IMAGENES, ACTITUDES Y VALORACIONES. - II. FINANCIACION DE LOS PARTIDOS Y OPINIÓN PÚBLICA. - III. FINANCIACION PRIVADA DE LOS PARTIDOS: UNA PROSPECTIVA.-CONSIDERACIONES FINALES. 


\title{
5. LA FINANCIACIÓN DE LOS PARTIDOS POLÍTICOS ANTE LA OPINIÓN PÚBLICA
}

\author{
POR \\ Pilar del Castillo \\ Profesora Titular de Ciencia Política
}

UNED

INTRODUCCIÓN

En la todavia breve historia del nuevo sistema democrático español, la financiación de los partidos políticos ha registrado un proceso de una creciente estatalización. La ayuda económica que el Estado comenzó a prestar a las organizaciones políticas con ocasión de las primeras elecciones democráticas de 1977 ha ido ampliándose al extremo de constituir hoy la primera y casi exclusiva fuente de financiación de los grupos mayoritarios ${ }^{1}$. El papel que en España desempeña las subvenciones públicas en la financiación de los partidos políticos es de una importancia notablemente superior al que tiene en cualquier otra democracia europea. Las causas que han motivado esa situación son de índole diversa; uno de los argumentos más frecuentes esgrimidos por los partidos políticos se centra en su propia debilidad organizativa. Esta situación es atribuida esencialmente a la juventud de la democración española y a la imposibilidad, por consiguiente, de desarrollar partidos de masas en tan corto período de

1 Asi resulta, por ejemplo, en el Informe emitido por el Tribunal de Cuentas sobre la regularidad de las contabilidades electorales relativas a las elecciones generales de 1986, ver Pilar DEL CASTILLO, «Financiación de las elecciones generales de 1986", en Revista de Derecho Político. UNED, Madrid 1988, n, ${ }^{\circ} 25$, págs. 130-131. 
tiempo. A partir, entre otros, ${ }^{2}$ de ese argumento, se considera que el Estado debe garantizar los suficientes recursos económicos a los patidos para que éstos cumplan las funciones que tienen constitucionalmente reconocidas.

Desde esa perspectiva, los partidos parlamentarios han diseñado un sistema que no limita las cantidades que anualmente puedan ser consignadas en los Presupuestos Generales del Estado con destino a la financiación de sus actividades ordinarias. Estas «facilidades legales» han permitido un incremento anual de los subsidios ordinarios en ocasiones muy notables; el mayor de los incrementos se produjo en 1987 y se situó en un 100 por 100 respecto del año anterior.

Las posibilidades de financiación privada de los partidos no parecen ser, sin embargo, tan escasas como podria desprenderse del extraordinario peso que tienen las subvenciones del Estado, al menos eso sugieren algunos datos de opinión pública. En este trabajo se analizan los resultados de dos encuestas Ilevadas a cabo por el Centro de Investigaciones Sociológicas, en las que se incluyeron diversos indicadores sobre la financiación de los partidos políticos ${ }^{3}$. Con el fin de contextualizar el tema que aquí nos ocupa, se incluyen, en una primera parte, algunos datos relevantes, procedentes de las mismas encuestas, acerca de la actitud general de los españoles hacia los partidos.

\section{LOS PARTIDOS ANTE EL ELECTORADO: IMÁGENES, ACTITUDES Y VALORACIONES}

En la Tabla 1 aparecen los resultados de distintas opiniones, agrupadas en categorías positiva y negativa, sobre el papel que desempeñan los partidos políticos. En términos generales, se puede afirmar que los españoles conceden a los partidos un papel esencial en el funcionamiento del sistema democrátivo. Dos tercios de la población considera que son necesarios para defender los distintos intereses sociales o para participar en la vida política y un porcentaje similar cree que son condición indispensable para la existencia misma de la Democracia. Frente a esas opiniones positivas y legitimadoras de los partidos políticos, sólo un 17 por 100 considera que son organizaciones que no tienen utilidad alguna.

2 Para una discusión más detallada sobre el tema: Pilar DEL CAstillo, La financiación de partidos y candidatos en las democracias occidentales. Centro de Investigaciones Sociológicas, Madrid 1985, págs. 65-67 y 200-216.

${ }_{3}$ Estudio CIS 1740: Barómetro de Opinión Pública, junio, 1988. Estudio CIS 1788: Monográfico «Cultura Política», enero, 1989. 
TABLA 1. OPINIONES SOBRE LOS PARTIDOS POLÍTICOS

ACUERDO DESACUERDO NS. NC.

\section{Opiniones positivas}

Los partidos son necesarios para defender los intereses de los distintos grupos y clases sociales

67

62

62

Sin partidos no puede haber democracia

Gracias a los partidos la gente puede participar en la vida política española

\section{Opiniones negativas}

Los partidos políticos sólo sirven para dividir a la gente

Los partidos se critican muchos entre sí, pero en realidad todos son iguales

Los intereses que persiguen los partidos tienen poco que ver con los de la sociedad

Los partidos no sirven para nada

par....................................

32

33

$17 \quad 3$

Hay opiniones «negativas» que concitan, no obstante, significativos porcentajes de acuerdo. Si en términos globales los partidos cuentan con un amplio grado de legitimación, cuando se trata de opiniones que hacen referencia a su actividad los resultados son menos satisfactorios. Así, un 32 por 100 considera que persiguen intereses partidistas alejados de los verdaderos problemas de la sociedad y casi la mitad de los españoles cree que no han sabido interesar a los ciudadanos en los asuntos políticos. Por otra parte, hay que señalar que al observar las series temporales de estos 
indicadores durante el período 1987-1989 se ha reducido, en algunos casos, hasta nueve puntos, el acuerdo respecto de las opiniones positivas.

La valoración que merecen la honestidad y la credibilidad de los líderes políticos constituye también un buen reflejo de la actitud crítica que los españoles mantienen sobre la actuación de los partidos en nuestro sistema democrático. Según una mayoria absoluta de los encuestados, en ninguno de los dirigentes de los cuatro principales partidos nacionales prima la preocupación de los intereses del país sobre los intereses de naturaleza partidista (Tabla 2). Los dirigentes de esas cuatro formaciones políticas tienen poca o ninguna honradez en opinión de mayorías relativas del electorado; entre tres y cuatro de cada diez españoles sostienen esa opinión. Por otra parte, la desconfianza de los electores hacia los líderes políticos es muy notable a tenor de los resultados que arroja el indicador de la credibilidad; entre siete y ocho de cada diez españoles sólo algunas veces o casi nunca creen lo que dicen líderes de los partidos citados (Tabla 2)

TABLA 2. HONESTIDAD Y CREDIBILIDAD DE LOS LIDERES POLITICOS, SEGÚN EL RECUERDO DE VOTO EN LAS ELECCIONES GENERALES DE 1986

A) PREOCUPACIÓN DE LOS PARTIDOS POLITICOS POR LOS PROBLEMAS DEL PAIS EN RELACIÓN A LA QUE DEDICAN A INTERESES PARTIDISTAS

$$
(\% \text { Poco }+ \text { Nada })
$$

\begin{tabular}{|c|c|c|c|c|c|}
\hline & TOTAL & AP & $\operatorname{cDs}$ & IU & PSOE \\
\hline AP & 60 & 32 & 62 & 84 & 66 \\
\hline CDS & 58 & 58 & 39 & 79 & 62 \\
\hline IU $\ldots \ldots \ldots \ldots \ldots \ldots \ldots \ldots \ldots \ldots \ldots \ldots$ & 57 & 67 & 63 & 35 & 55 \\
\hline PSOE .................... & 51 & 68 & 62 & 69 & 30 \\
\hline
\end{tabular}


B) HONRADEZ DE LOS DIRIGENTES POLITICOS

$(\%$ Poco + Nada $)$

\begin{tabular}{|c|c|c|c|c|c|}
\hline \multicolumn{6}{|l|}{ DIRIGENTES } \\
\hline 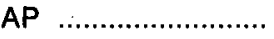 & 39 & 22 & 35 & 59 & 45 \\
\hline CDS & 38 & 39 & 20 & 53 & 40 \\
\hline IU & 37 & 50 & 38 & 15 & 36 \\
\hline PSOE & 36 & 53 & 41 & 47 & 25 \\
\hline \multicolumn{6}{|c|}{ C) CREDIBILIDAD DE LOS LIDERES POLITICOS } \\
\hline \multicolumn{6}{|c|}{ ( $\%$ Sólo algunas veces + Casi nunca) } \\
\hline LIDERES DE: & TOTAL & AP & $\cos$ & IU & PSOE \\
\hline 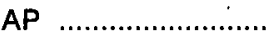 & 79 & 39 & 85 & 92 & 87 \\
\hline CDS $\ldots \ldots \ldots \ldots \ldots \ldots \ldots \ldots$ & 79 & 78 & 43 & 91 & 83 \\
\hline IU ........................... & 80 & 90 & 86 & 35 & 80 \\
\hline PSOE & 70 & 96 & 86 & 79 & 50 \\
\hline
\end{tabular}

Aun cuando los partidos son considerados piezas indispensables del sistema político, la significación que se les atribuye es menor de la que se le otorga a otras instituciones políticas. Mientras que un 66 por 100 considera que los partidos tienen una gran importancia, la misma opinión es mantenida respecto del Parlamento de la Nación por un 74 por 100 y en relación a los Ayuntamientos por un 80 por 100. Por otra parte, los problemas de los partidos suscitan un escaso interés, tan sólo el 20 por 100 dice encontrarse interesado en esa temática, un porcentaje bastante inferior al 
que se interesa por los problemas del Gobierno de la Nación, 48 por 100 , o de los Ayuntamientos, 61 por 100.

Entre las características de la reciente historia electoral de nuestro sistema democrático destaca la combinación de la estabilidad de ciertas actitudes ideológicas básicas y la volatilidad del voto en función de la oferta de los partidos. Una de la explicaciones de este fenómeno considera que el hecho de que los electores españoles no se encuentren enraizados en una tradición política familiar, en una red de relaciones organizativas o en una subcultura ideológica los hace mucho más susceptible de responder a la situación concreta y a las ofertas políticas del momento ${ }^{4}$. No es de extrañar por ello que una mayoria absoluta de los españoles crea que, frente a sus aparentes disidencias, los partidos son bastante parecidos entre sí. Este dato sugiere por sí sólo la existencia de un bajo nivel de identificación partidistas, como efectivamente expresan los datos resultantes cuando se utiliza especificamente ese indicador: un 47 por 100 de los entrevistados no se identifica con ningún partido político y, entre quienes dicen estarlo, los fuertemente identificados constituyen un 13 por $100^{5}$. España presenta el nivel de identificación partidista más bajo de las democracias europeas: La diferencia, incluso con Grecia y Portugal, paises con los que comparte un pasado autoritario y la bisoñez de su sistema democrático, resulta igualmente muy notable (Tabla 3).

La afiliación a los partidos políticos presenta, igualmente, los niveles más bajos de toda la Europa democrática. Los grandes partidos (PSOE y PP) escasamente superan los 200.000 afiliados cada uno y en conjunto sólo el 3 por 100 de los españoles pertenece a alguna organización política. Siendo cierto que el asociacionismo se encuentra poco extendido, otro tipo de asociaciones resultan más atractivas que los partidos. Así, por ejemplo, un 13 por 100 dice pertenecer a alguna asociación deportiva, un 10 por 100 de asociaciones de vecinos y un 8 y 7 por 100 a asociaciones culturales y sindicales (Tabla 4).

\section{FINANCIACIÓN DE LOS PARTIDOS Y OPINIÓN PÚBLICA}

A pesar de que los partidos mayoritarios se financian casi en esclusiva con dinero público, sólo un 58 por 100 de los españoles saben que

4 Esta es la tesis sostenida por J. LINZ en Crisis y cambio: electores y partidos en la España de los años ochenta, J. Linz y J. R. MONTERo (eds), Centro de Estudios Constitucionales, Madrid 1986, pág. 658.

5 Un amplio tratamiento del tema se encuentra Pilar del CAstillo, Notas sobre la identificación partidista (Extensión y utilidad del concepto en España). Trabajo presentado en el Congreso anual de la Asociación Española de Ciencia Política y Derecho Constitucional, Gerona, 16-18 de marzo, 1989. 
TABLA 3. IDENTIFICACIÓN PARTIDISTA EN LOS PAISES MIEMBROS DE LA COMUNIDAD ECONÓMICA EUROPEA * 
TABLA 4. AFILIACIÓN A DIVERSAS ASOCIACIONES SEGÚN EL RECUERDO DE VOTO EN LAS ELECCIONES GENERALES DE 1986

ज्ञ

\begin{tabular}{|c|c|c|c|c|c|c|c|c|c|}
\hline & TOTAL & AP & $\cos$ & IU & PSOE & OTROS & $\begin{array}{l}\text { NO } \\
\text { VOTO }\end{array}$ & N.S. & N.C. \\
\hline $\begin{array}{l}\text { Asociaciones benéficas o } \\
\text { religiosas }\end{array}$ & 7 & 14 & 5 & 4 & 5 & 6 & 7 & 5 & 7 \\
\hline Asociaciones culturales . & 8 & 10 & 8 & 13 & 8 & 18 & 10 & 2 & 5 \\
\hline $\begin{array}{l}\text { Asociaciones deportivas } \\
\text { o recreativas }\end{array}$ & 13 & 10 & 16 & 21 & 12 & 23 & 18 & 5 & 13 \\
\hline 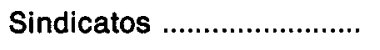 & 7 & 4 & 4 & 31 & 11 & 7 & 4 & 1 & 4 \\
\hline Partidos políticos ................ & 3 & 4 & 2 . & 15 & 4 & 10 & 0 & 0 & 1 \\
\hline Asociaciones de vecinos & 10 & 12 & 13 & 19 & 10 & 12 & 7 & 8 & 11 \\
\hline Asociaciones de mujeres & 2 & 3 & 2 & 2 & 2 & 2 & 1 & - & 2 \\
\hline $\begin{array}{l}\text { Organizaciones interesa- } \\
\text { das por los derechos } \\
\text { humanos }\end{array}$ & 1 & 1 & 1 & 3 & 2 & 2 & 1 & 1 & 0 \\
\hline $\begin{array}{l}\text { Grupos ecologistas o pa- } \\
\text { cifistas }\end{array}$ & 1 & 0 & 1 & 4 & 1 & 4 & 2 & 0 & 1 \\
\hline $\begin{array}{l}\text { Asociaciones de consu- } \\
\text { midores }\end{array}$ & 1 & 2 & 2 & 1 & 2 & 2 & 1 & 0 & 1 \\
\hline $\begin{array}{c}\text { Asociaciones o Colegios } \\
\text { Profesionales }\end{array}$ & 4 & 4 & 6 & 5 & 3 & 5 & 4 & 1 & 4 \\
\hline 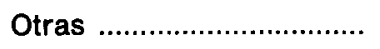 & 3 & 4 & 5 & 6 & 2 & 3 & 3 & 1 & 3 \\
\hline
\end{tabular}


reciben ayuda económica del Estado. Con independencia del conocimiento de este hecho, el 38 por 100 opina que los partidos deben financiarse exclusivamente con las contribuciones de sus militantes y simpatizantes. El 30 por 100 sostiene una opinión matizadamente diferente del anterior al considerar que aunque aquélla debiera constituir la principal fuente de recursos económicos el Estado ha de prestar también su colaboración. Sólo un 7 por 100 es favorable a que el Estado corra íntegramente con el sosteniendo económico de los partidos.

Al considerar algunas variables sociodemográficas básicas, tales como sexo, edad y nivel de estudios se producen ciertas diferencias de opinión (Tabla 5). En primer lugar, y como suele ser habitual ante un tema de opinión, las mujeres, los que tienen una edad más avanzada y los que presentan un menor nivel de instrucción registran un mayor porcentaje de no respuesta. Entre aquellos que opinan, las mujeres son menos favorables que los hombres a un sistema de financiación de los partidos en el que la única fuente de recursos económicos de éstos esté constituida por las aportaciones de sus militantes y simpatizantes (opción 1) pero también apoyan en menor medida un sistema en el que el Estado sea copartícipe en la financiación de los partidos (opción 2).

La edad introduce diferencias significativas respecto de la opción 2. A medida en que se avanza en los grupos de edad, desciende el porcentaje de quienes apoyan esa segunda opción. En las restantes opciones - financiación totalmente privada o a cargo del Estado- no se producen diferencias de opinión tan relevantes. El nivel de estudios resulta discriminante de forma significativa respecto de la opción «semi-estatal». Aquellos que tienen un mayor nivel de instrucción son más favorables hacia una intervención del Estado, llegando a producirse una diferencia de 27 puntos porcentuales entre la minima y la máxima categoría de estudios (Tabla 5). El grupo de «estudios superiores» es el único en el que mayoritariamente se apoya la segunda opción: 47 por 100 a favor de ella frente a un 37 por 100 favorable a la primera.

En la Tabla 5 se recoge, igualmente, los resultados de la opinión acerca de las tres opciones de financiación según la variable clase social subjetiva. Congruentemente con los resultados que se producen cuando se considera el impacto del nivel de estudios, aquellos que se autoposicionan en la clase media alta (obviamos la clase alta ya que sólo aparecen tres casos en la muestra), a los que hay que presumir un nivel de educativo más elevado, son los más favorables a la intervención del Estado. La simpatía por esta opción se reduce a medida en que se desciende en la clase social, siendo la clase trabajadora la que le presta un menor apoyo. No obstante, esa alternativa es todavía sustentada en menor medida por quienes consideran que no pertenecen a ninguna clase social, este grupo constituye un tercio de la muestra. 
TABLA 5. OPINIÓN SOBRE LA FINANCIACIÓN DE LOS PARTIDOS SEGÚN DIFERENTES VARIABLES SOCIO-DEMOGRÁFICAS Y CLASE SOCIAL SUBJETIVA

\begin{tabular}{|c|c|c|c|c|c|}
\hline \multirow[b]{2}{*}{ PORCENTAJE FILA } & (1) & (2) & (3) & \multirow[b]{2}{*}{$\begin{array}{l}\text { NO } \\
\text { SABE }\end{array}$} & \multirow[b]{2}{*}{ (N) } \\
\hline & $\begin{array}{l}\text { FINANCIAC. POR } \\
\text { MILITANTES } Y \\
\text { SIMPATIZANTES }\end{array}$ & $\begin{array}{l}\text { MLLITANTES Y } \\
\text { SIMPATIZANTES } \\
\text { MAS AYUDA } \\
\text { ESTATAL }\end{array}$ & $\begin{array}{c}\text { SOLO } \\
\text { FINANCIACION } \\
\text { ESTATAL }\end{array}$ & & \\
\hline \multicolumn{6}{|l|}{ Sexo } \\
\hline 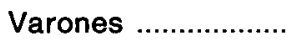 & 42 & 34 & 7 & 17 & (1.598) \\
\hline Mujeres ..................... & 35 & 27 & 8 & 31 & $(1.743)$ \\
\hline \multicolumn{6}{|l|}{ Edad } \\
\hline 18-25 años ............... & 39 & 36 & 9 & 17 & (651) \\
\hline 26-40 años ................. & 41 & 36 & 8 & 16 & (886) \\
\hline 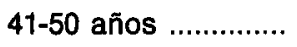 & 39 & 34 & 7 & 18 & (563) \\
\hline 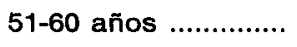 & 39 & 27 & 5 & 28 & (534) \\
\hline 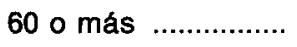 & 34 & 18 & 7 & 31 & (702) \\
\hline \multicolumn{6}{|l|}{ Educación } \\
\hline $\begin{array}{l}\text { Menos de } \\
\quad \text { primarios .............. }\end{array}$ & 33 & 20 & 6 & 40 & (995) \\
\hline Primarios ................... & 42 & 29 & 8 & 21 & (1.186) \\
\hline Bachiller .................... & 40 & 37 & 8 & 15 & (803) \\
\hline Superiores .............. & 38 & 47 & 6 & 9 & (352) \\
\hline \multicolumn{6}{|l|}{$\begin{array}{l}\text { Clase social } \\
\text { subjetiva }\end{array}$} \\
\hline Alta & - & 100 & - & - & (3) \\
\hline Media Alta .............. & 37 & 52 & - & 18 & (28) \\
\hline Media & 36 & 40 & 8 & 18 & (826) \\
\hline Media Baja .............. & 46 & 33 & 10 & 17 & (130) \\
\hline Trabajadora ............. & 42 & 30 & 8 & 18 & (752) \\
\hline $\begin{array}{l}\text { No pertenece a } \\
\text { ninguna clase } \ldots . .\end{array}$ & 39 & 26 & 7 & 21 & (990) \\
\hline
\end{tabular}


GRÁFICO I. OPINIÓN SOBRE LA FINANCIACIÓN DE LOS PARTIDOS SEGÚN AUTOUBICACIÓN EN LA ESCALA IZQUIERDA-DERECHA (AGREGADA)

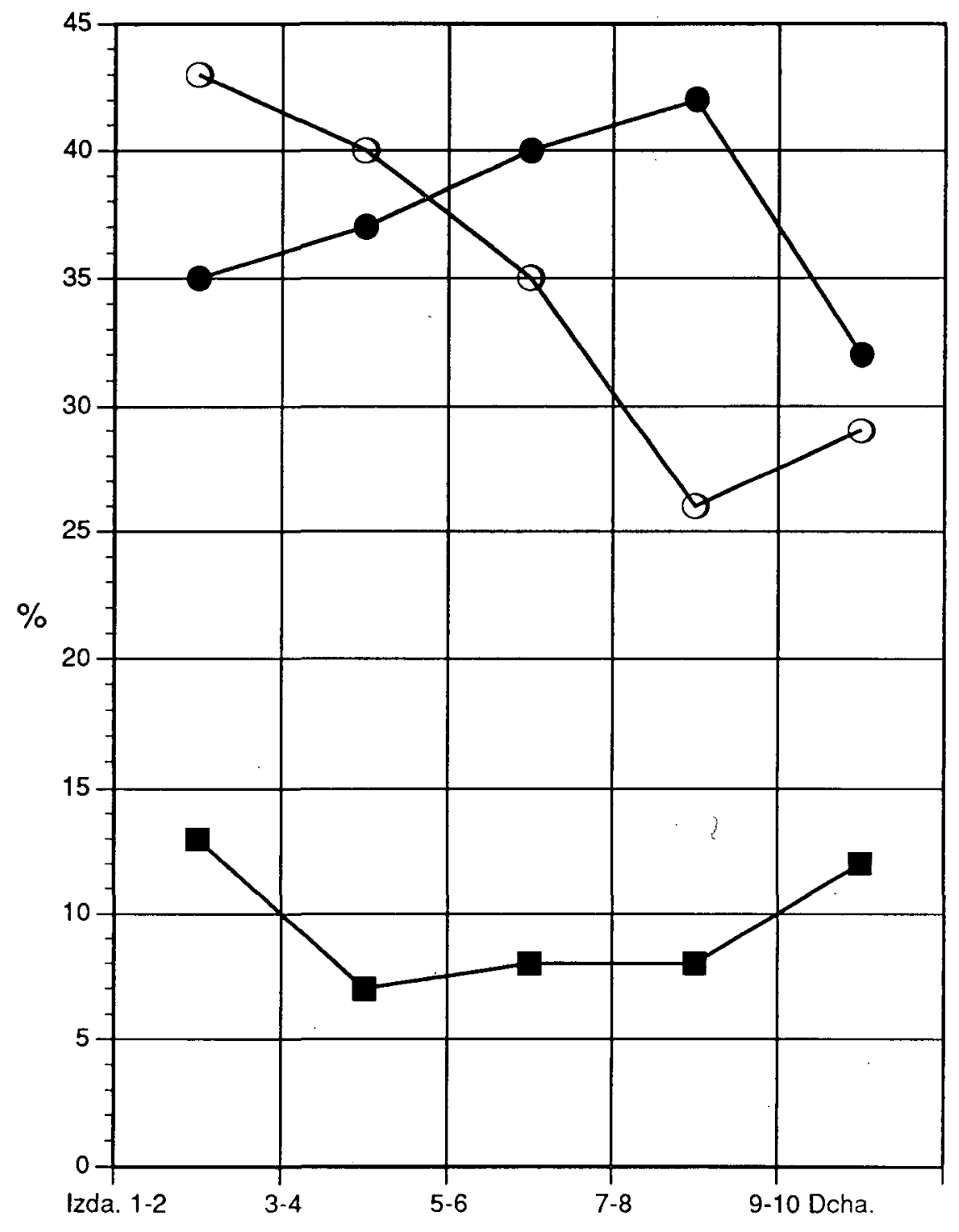

- Sólo Privada $\quad$ - Privada y Pública Sólo Pública 
GRÁFICO II. OPINIÓN SOBRE LA FINANCIACION DE LOS PARTIDOS SEGÚN EL RECUERDO DE VOTO EN LAS ELECCIONES GENERALES DE 1986

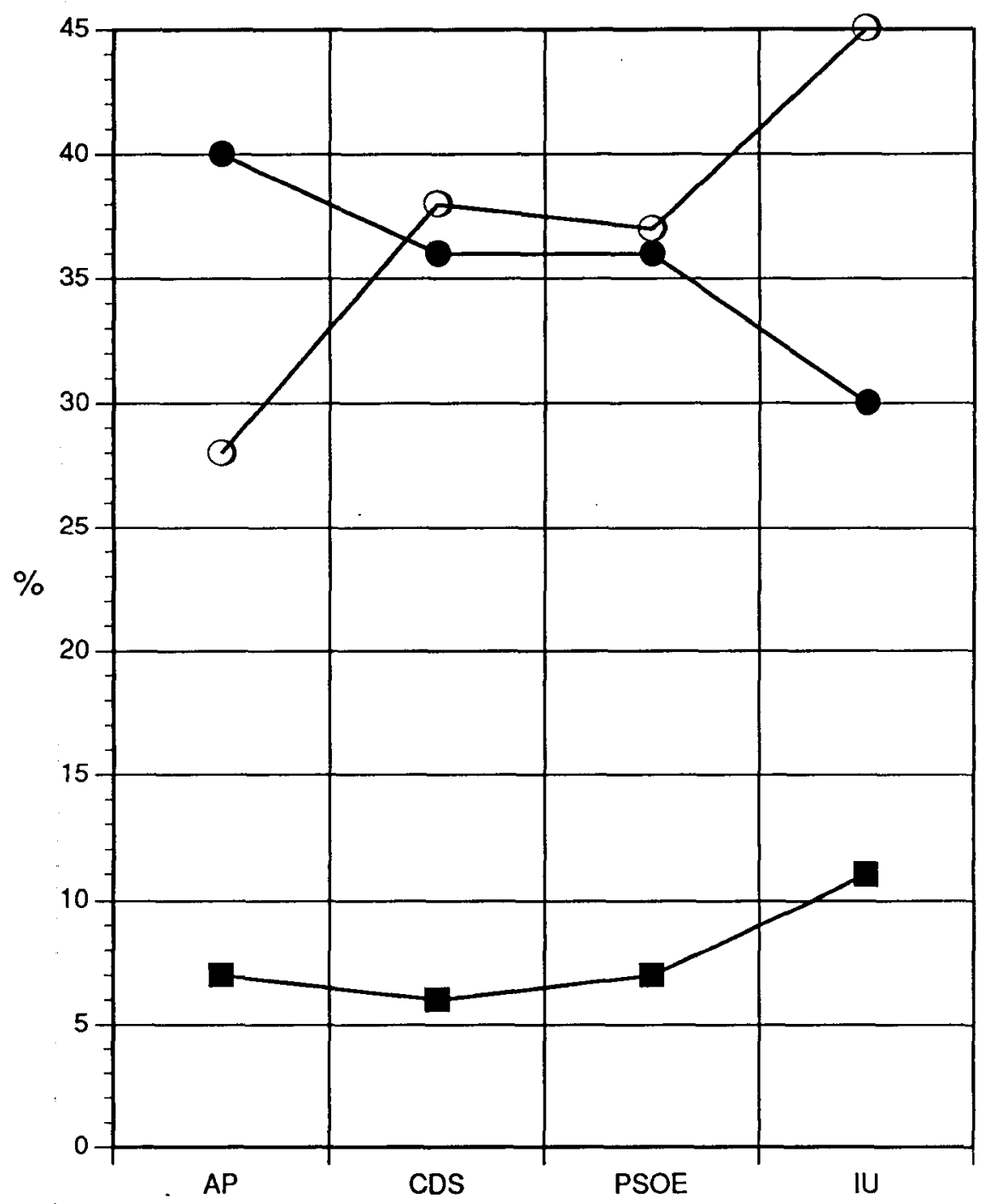

- Sólo Privada 
Los Gráficos I y II expresan las diferencias que presenta la opinión cuando se utilizan dos variables ideológico-políticas. En primer lugar, se ha considerado la opinión según la auto-ubicación ideológica del entrevistado expresada en una escala de 1 a 10 (Gráfico I). Entre quienes se sitúan en posiciones de centro y de derecha (pero no así de extrema derecha) existe un mayor apoyo a la autofinanciación de los partidos y sobre todo un apoyo sensiblemente inferior a la intervención estatal (opción 2). La responsabilidad plena del Estado (opción 3 ), aunque es minoritaria respecto de las otras alternativas en todos los grupos de la escala ideológica, encuentra un apoyo significativamente superior a la media en las posiciones de extrema izquierda y extrema derecha.

A considerar la relación entre opinión y preferencia partidista - Gráfico II- (ésta se operacionaliza según el voto declarado en las elecciones generales de 1986) nos encontramos con resultados sustancialmente coherentes con los que arrojaba la variable ideológica. Asi, el electorado del Partido Popular es el más inclinado a la autofinanciación de los partidos y el menos favorable a la intervención del Estado. En el extremo opuesto se sitúan los votantes comunistas (IU) quienes, por el contrario, defienden en mayor proporción que ningún otro la opción «semi-estatal». Como se puede observar, los votantes del grupo centrista (CDS) y de los socialistas (PSOE), mantienen opciones similares y se dividen en proporciones casi iguales entre el apoyo a la opción 1 y a la opción 2. La tercera de las opciones es apoyada por porcentajes minoritarios de todos los grupos de votantes aunque el electorado comunista simpatiza con ella en una mayor medida que los restantes.

\section{FINANCIACION PRIVADA DE LOS PARTIDOS: UNA PROSPECTIVA}

Dado el bajo nivel de afiliación y la escasa identificación partidista no es de extrañar que sólo un 24 por 100 de los españoles se muestre dispuesto a contribuir a financiar el partido político de su preferencia y ello a pesar de que, como hemos visto, un 68 por 100 considere que la primera fuente de obtención de recursos económicos deben ser los simpatizantes y los militares. Un 22 por 100 de los entrevistados considera poco probable que se decidiera a colaborar, un tercio del electorado declara que de ninguna manera contribuiría y, finalmente, un 20 por 100 no mantiene opinión.

Según las variables sociodemográficas anteriormente consideradas, los más dispuestos a colaborar son los hombres, el grupo de edad comprendido entre los veintiuno y los cuarenta años y en especial los que tienen estudios superiores ( $42 \%$ ) y los que pertenecen a la clase media alta $(54 \%)$. La disposición a contribuir desciende, por otra parte, entre aquellos 
que se sitúan en las zonas más centrales de la escala de ideología. Como refleja el Gráfico III, los más reluctantes son los que se autoclasifican en posiciones de 5 y 6 . Por el contrario, los que se ubican en los puntos más extremos (tanto a la derecha como a la izquierda) se muestran más favorables a prestar su apoyo a las organizaciones políticas con las que simpatizan. Si consideramos la preferencia partidista (Gráfico IV) se observa que el electorado más favorables a contribuir es el comunista (es también el que presenta un nivel de identificación partidista más elevado). A una distancia notable se sitúan, en segundo lugar, los votantes conservadores que, no obstante, presentan un porcentaje de potenciales contribuyentes superio a la media ( $32 \%$ ). El electorado socialista resulta el menos predispuesto a contribuir: sólo un 24 por 100 de ese grupo de votantes se muestra favorable.

\section{CONSIDERACIONES FINALES}

Entre los especialistas en la financiación de los partidos existe un acuerdo bastante generalizado, con argumentos cuyo desarrollo sobrepasa el objetivo de este trabajo, a favor de cierto grado de financiación pública. Simultáneamente se considera que una participación significativa del electorado en la financiación de las organizaciones partidistas resulta muy saludable para el sistema democrático. En primer lugar, porque implica la participación de los ciudadanos en el sostenimiento de sus instrumentos organizados de expresión política y defensa de sus intereses y en segundo término, ya que favorece la consolidación de los partidos al facilitarles unas fuentes amplias y relativamente estables de financiación.

La hipótesis de que los principales partidos políticos españoles llegaran algún día a convertirse en organizaciones de masas no se encuentra avalada por las características de la sociedad española en la que emerge el nuevo sistema democrático y con él los partidos políticos. Las condiciones (en especial por lo que se refiere a la intensidad de las escisiones sociales -cleavages- en torno a ejes tradicionales como el económico, ideológico o religioso entre otros) que permitieron en el perlodo de entreguerras e, incluso, después de la Segunda Guerrra Mundial el desarrollo en diversos países europeos de partidos de masas, se encuentran en sus dimensiones más sustantivas ausentes en la sociedad española actual. Es ésta una sociedad que por el contrario se caracteriza, de forma semejante a otras sociedades post-industriales, por la inexistencia de una polarización ideológica significativa. Pero a diferencia de esos otros sistemas políticos, el nuevo sistema democrático español prácticamente desconoce las tradiciones partidistas familiares, al haber quedado sepultadas en el transurso 
GRÁFICO III. DISPOSICIÓN A CONTRIBUIR A LA FINANCIACIÓN DE LOS PARTIDOS SEGÚN AUTOUBICACION EN LA ESCALA IZQUIERDA-DERECHA (AGREGADA)

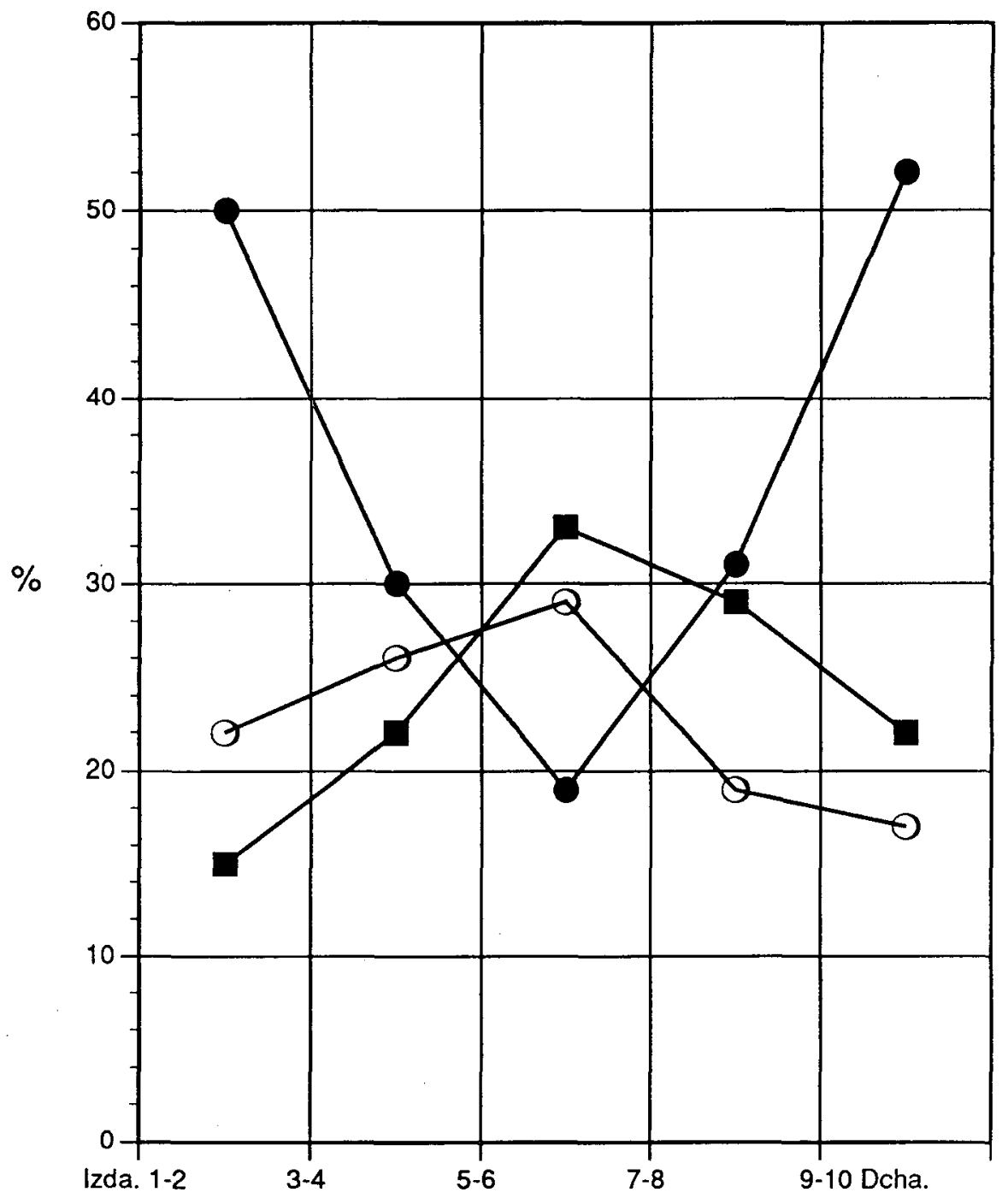

- Contribuiría $\odot$ Probablemente no $\rightarrow-$ No, con seguridad 
GRÁFICO IV. DISPOSICIÓN A CONTRIBUIR A LA FINANCIACIÓN DE LOS PARTIDOS SEGÜN EL RECUERDO DE VOTO EN LAS ELECCIONES GENERALES DE 1986

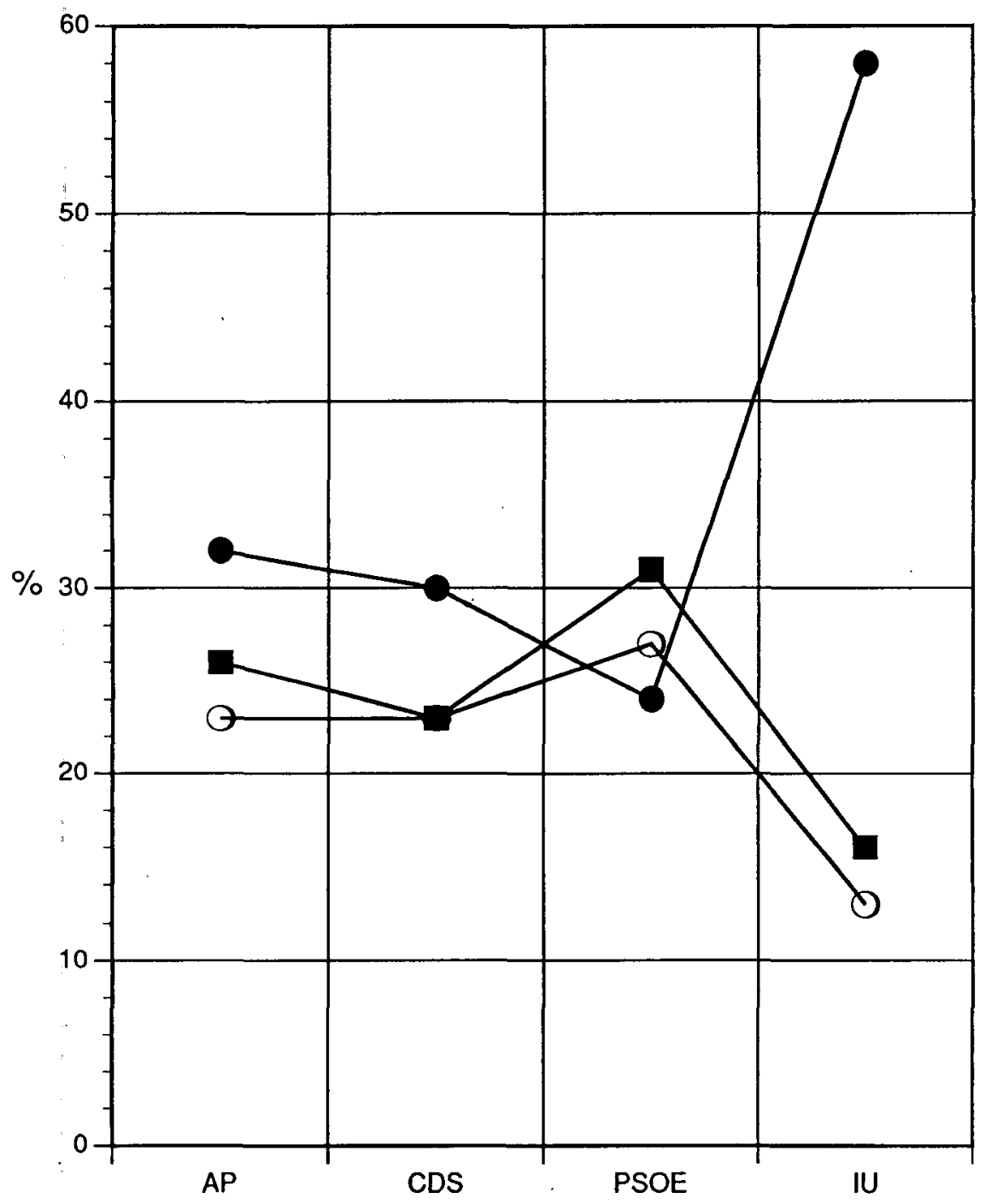

- Contribuiría $\odot$ Probablemente no $\rightarrow-$ No, con seguridad 
de los cuarenta años del sistema autoritario precedente ${ }^{7}$. La posibilidad de que los partidos políticos españoles lleguen a tener en su militacia una fuente importante de financiación carece por las razones apuntadas de argumentos sólidos. Ello no significa, en mi opinión, que los partidos no alcancen a estabilizar las simpatías y fidelidades de amplios sectores de su propio electorado, esto es, a consolidar niveles más altos de identificación partidista. El logro de esos objetivos se encuentra condicionado por la falta de estabilidad del sistema de partidos que no parece encontrar un perfil definitivo. Esta situación problematiza, sin duda, el desarrollo de un sistema de financiación de las organizaciones políticas esencialmente basado en sus votantes más estables. No obstante, hoy los grandes partidos tienen posibilidad de comenzar a desarrollar esa vía de financiación a la que aparecen ofrecer su apoyo, si nos atenemos a los datos de opinión recogidos en páginas anteriores, porcentajes de una cierta significación entre los distintos grupos de votantes. Obviamente es éste un sistema organizativamente más costoso de operacionalizar que cargar la financiación de los partidos a los Presupuestos Generales del Estado, cuando además los interesados, esto es, los partidos parlamentarios, pueden decidir sin limitación alguna, como ocurre en la actualidad, la cantidad anual con la que obligatoriamente los españoles van a contribuir. Es, sin embargo, un sistema que opta por favorecer la participación política y fortalecer las relaciones entre los partidos y la sociedad.

J. LiNz desarrolla ampliamente esta tesis en Crisis y cambio..., cit, págs. 